\title{
浅析“00 后”少数民族大学生思想政治教育管理
}

\author{
穆再排尔・安外尔 \\ 南京工业大学 \\ DOI:10.32629/er.v3i7.2921
}

\begin{abstract}
[摘 要] 思想政治教育在高校众多教育教学课程中有着十分重要的作用, 由于它能够帮助学生树立正确的 三观,同时提升自身的爱情情怀。尤其针对高校大学生中的少数民族群体,思政教育一方面可以使这部分学 生更好地融入大学生活,另一方面也有利于培养和提升这部分学生的自豪感以及民族认同感,有利于少数 民族学生群体端正自己的民族观。因此, 本文以 “00后” 少数民族大学生思想政治教育管理为研究课题, 在 简要介绍了背景后, 提出针对性的解决对策, 以期促进 “00后”少数民族大学生思想政治教育管理。
\end{abstract}

[关键词] 少数民族; 大学生; 思想政治; 教育管理

中共十九全国代表大会以来, 党中央 对思想政治教育课程的建设十分重视。思 想政治教育课程建设获得逐步改善, 大学 生对学习思想政治教育课程的学习水平 已显著提高, 标志中国特色社会主义已经 进入了一个新时代。新时期高校思想政治 课程教学改革必须顺应时代的呼声, 与时 俱进, 以新时代的视野来研究思想政治课 程的创新, 提高教育教学的质量和水平。

思想政治课程作为一门全国性的法 定课程, 其目的是提高学生的思想品德和 法治水平, 它始终在学生思想政治教育和 价值观教育中发挥着十分积极和重要的 作用。尤其是对 “ 00 后” 高校学生中的少 数民族群体而言, 这部分学生一方面是其 民族形象的代表, 另一方面也承担着民族 团结以及发展的重任, 所以对这部分学生 群体组织开展思政教育具有非常重要的 意义。本文将针对 “ 00 后” 高校学生中的 少数民族群体的思政教育进行分析, 对起 管理办法和措施进行讨论。

\section{1 运用网络教育载体, 创新思 想政治教育方法}

“00后”高校大学生本身就具有与 90 后大学生群体不同的特点, 同时其中 的少数民族群体又有着自己的特殊性, 所以如果仍然针对这部分群体展开单一 性的课堂教学, 必然会使得这部分群体 的教育教学需求得不到充分的满足。

观察现阶段国内少数民族群体的思
政教育情况能够看出, 当前大部分少数民 族大学生教师在教学过程中的思想存在 局限, 在教学过程中很多教师都是以自己 为主导, 尽管很多学生逐渐适应和习惯了 这种被动式的学习和接收方式, 然而思政 教育的精准度仍然非常低, 无法充分满足 学生群体的心理需求, 特别是少数民族学 生群体的一些特殊需求, 对思政教育教学 工作的开展产生了非常严重的负面影响。

由于互联网的迅猛发展, 新一代年轻 群体在网络中的活跃度非常高, 所以对这 部分群体的思政教育也应当集中到网络这 一场所中。当前很多 00 后学生群体都是通 过网络了解信息和知识, 而对少数民族高 校学生的思政教育也应当充分发挥网络媒 介的作用, 应当借助于三大团体将学生凝 聚起来, 将班级和学校作为开展思政教育 和落实思政教育目标的重要场所 ${ }^{[1]}$ 。想要改 善这一教学弊端, 教师需要通过满足 “ 00 后” 少数民族大学生身心发展的需要, 注重 思想政治教育的重要性, 充分发挥学生意 识的主导作用, 才能提高思想政治课程的 教学质量。教师应更新他们的传统思想以 及固话和单一的教学方法, 创新能够适应 新时达发展和学生自身发展所需的教学方 法, 吸引思想活跃的 “ 00 后” 少数民族大学 生。因此, 教师需要运用灵活多变的方法来 增加课堂教学的吸引力, 运用让 “ 00 后” 少 数民族大学生真正参与教学的现代教育方 法。借助网络信息技术采用多媒体教学方法,
帮助学生在学习思想政治课程的过程中收 获快乐, 以此增加学生学习的兴趣和意愿。

\section{2 结合少数民族文化, 嵌入思 想政治教育目标}

相较于汉族的高校学生而言, 少数民 族学生所处的生活和学习环境以及接受 的文化熏陶都有其特殊性, 所以思政教育 学习也会比较特殊。由于少数民族学生与 汉族学生的认知能力以及心理需求都有 显著的差异, 因此教师在开展思政教育教 学工作时应当综合考量少数民族学生的 特性, 尤其是文化的特征, 在开展教育教 学工作时应当融合思想政治教育内容。例 如, 少数民族的传统节日即将来临之时, 教师应当借助于线上平台为少数民族学 生组织开展相应的节庆活动, 也可以结合 民族的节日设计一个特殊的网课, 通过教 学工作的开展融入中国人团结一致的思 想。这不仅有效地动员了对少数民族大学 生对学习的关心, 也使少数民族大学生在 潜移默化中能接受深刻的思想政治教育, 从而促进思政教育精准度的提升。

同时由于民族文化对于少数民族学 生的成长起到了非常重要的作用, 所以 少数民族学生往往有着比较强的文化以 及宗教思想, 这种思想对于少数民族学 生的思政教育工作而言既有益处也有不 利之处, 教师在教学工作中应当积极采 取措施对教育资源进行科学的挖掘和利 用, 有利于提高少数民族大学学生的思 
想水平。同时也需要注意到, 如果有一些 极端宗教人士或者是恐怖主义人士以及 其他存在不良意图的人士, 利用少数民 族学生的宗教思想或者民族观念组织开 展不法的活动, 则很可能会对这部分学 生的思政观念产生负面影响 ${ }^{[2]}$ 。所以, 教师在对少数民族学生开展思想政治教 育时, 还需要积极采取措施运营公众平 台, 特别是新媒体平台, 应当通过平台的 运营尽可能避免不良意图人士借助于平 台传播不法言论, 从而影响学生群体的 思想观念, 促进思政教育教学目标的落 实, 提高思政教育教学工作的精准度。

\section{3 根据少数民族特性, 优化思 想政治教育氛围}

目前, “00后” 后大学生, 他们的想 法更加多样化, 思考问题的方式不同于 以往学生的思考方式。他们思维活跃, 有 很强的独立性, 但是很容易受一些金钱 思想的影响, 他们大多以自我为中心, 并 且有着十分强烈的自我心理, 因此, 需要 在教育管理中, 优化思想政治教育氛围。

对于少数民族学生的思政教育应当建 立健全相应的教育体系, 应当将 “预防” 和 “疏导”进行有机的融合。具体而言, 教师 在思政教育教学工作中需要积极和学生交 流, 通过交流了解学生当前的人际关系和 生活状况, 同时还需要掌握学生的学习和 思想状况。其中 “预防” 是指学生以及辅 导员借助于宿舍或班级有针对性的解决一 些比较普遍的问题, 充分发挥团队帮扶的 作用, 辅助学生及时确定合理的解决办法 并构建相应的体系, 借助于该体系为其他 问题的解决提供可参考的路径 ${ }^{[3]}$ 。

“疏导” 是指高校辅导员面向各个 学生组织开展 1 对 1 的对话, 通过这种对 话发现学生群体的需求和问题, 了解学 生群体的实际情况, 基于此采取更加有 针对性的方法和措施帮助学生解决问题, 使他们融入到新的生活以及学习环境中, 从而为其更好的进入学习状态提供帮助 和引导。除此之外, 辅导员在与多名学生 进行群体性的谈话时应当在发现问题之 后迅速采取措施使问题得到解决。

4 坚持教育管理原则, 丰富思 想政治教育内容
在对 “ 00 后” 少数民族大学生思想政 治教育管理管理中, 需要坚持“严、爱、细、 恒” 的教育原则, 并丰富教育管理内容, 以 此加强对少数民族大学生思想政治教育于 管理。具体而言, 从以下几方面展开:

一是要针对日常管理制定科学的管 理制度和体系, 使得安全稳定的底线得 到稳固。高校在管理少数民族学生群体 是一方面需要以纪律和制度的形式对其 进行规范, 对于任何违反纪律的行为必 须严加处理, 绝不能姑息容忍, 若是不能 及时处理, 很可能会导致学生形成特殊 化的思想。另一方面高校对于少数民族 学生的学业管理应当遵循公平公正的原 则, 对于任何少数民族学生都应当采取 统一的标准进行考核, 绝不能存在不上 课或者不认真学习就可以通过考核的情 况, 这样才可以使学生更好的成长。

二是对于少数民族学生的学习应当 给予充分的关怀。与汉族学生相比, 少数 民族学生在学习方面的基础相对比较差, 因此应当针对这部分学生加大对其学习 的支持力度, 教育和指导少数吗民族学 生, 使他们养成良好的学习习惯, 掌握正 确的学习方法, 特别是对成绩较差的学 生提供一对一的辅导和个别辅导, 帮助 他们提高自己的理解和认知能力以及学 习水平。同时高校还可以专门针对少数 民族学生组建相应的班级, 邀请一些学 习能力比较强并且学习成绩比较好的学 生或者是专业的教师为这部分学生讲解 课程, 一方面可以促进学生与教师之间 的交流和联系, 另一方面也可以有效调 动少数民族学生学习的主观能动性。

三是应当关注和关怀少数民族学生的 家庭生活, 因为部分学生的家庭可能比较 贫困, 所以在生活方面可能会出现一些问 题。对于此类问题, 辅导员和思政工作者应 当积极与学生进行沟通, 通过谈话或者谈 心的方式走入少数民族学生的内心, 对于 其生活应当有充分的关注。思政工作者在 日常管理中还应当发挥少数民族学生的宿 舍同学以及班级同学的力量, 发动这部分 学生为少数民族学生的学习和生活提供帮 助和关怀, 使得这部分学生可以迅速融入 到集体的氛围中 ${ }^{[4]}$ 。如果发现少数民族学生
的家庭较为贫困则需要用补助金来解决他 们的困难。对于有心理问题的少数学生民 族来说, 应该加强心理咨询和辅导。一部分 学少数民族学生可能因为语言或者是生活 习惯等各种因素而封闭自己, 不愿意与其 他学生或者老师进行沟通和交流, 对于此 类群体应当给予充分的关怀和爱护, 帮助他 们更快的融入到新的学习和生活环境中。

\section{5 结语}

要解决少数民族学生思政教育的问 题, 首先需要明确少数民族学生思政教育 工作是一项长期性的工作, 对于民族团结 和民族发展有非常重要的影响和意义, 所 以在新时期必须重视对少数民族高校学 生的思政教育工作和管理, 教师在教学工 作中应当积极创新对少数民族大学生思 想政治教育的思路和方法。在继承的基础 上创新, 深刻到认识新时期我国高等教育 的责任和使命, 加强少数民族大学生思想 政治教育与管理, 结合少数民族大学生的 特性, 以更加贴合少数民族学生特点的思 政教育方式组织开展思想政治教育, 从而 促进少数民族大学生思政教育精准度以 及教育水平和教育效率的提升。

\section{基金项目:}

南京工业大学2020年校党建与思想 政治教育研究课题(编号SZ20200322)。

\section{[参考文献]}

[1]黄鹤, 路日亮. 新时代少数民族大 学生思想政治教育实践育人路径探究 [J]. 贵州民族研究,2019,39(10):200-203.

[2]黄艳.少数民族大学生思想政治教 育路径创新研究——思想政治教育创新 研究系列论文之一 $[J]$.广西师范学院学报 (哲学社会科学版),2019,37(02):88-93.

[3]曹斌, 沈光涛. 少数民族大学生思 想政治教育特殊性分析[J].中国青年社 会科学,2019,34(04):117-120.

[4]乌斯满 - 达吾提, 郭文强. 少数民 族大学生思想政治教育生活化路径分析 [J]. 新疆师范大学学报(哲学社会科学 版),2019,33(05):50-54.

\section{作者简介:}

穆再排尔・安外尔(1995--), 男,维吾尔 族, 新疆喀什人, 助教, 南京工业大学少数民 族专职辅导员,研究方向: 思想政治教育。 